\begin{tabular}{c}
\hline GRUPO DE PESQUISA \\
COLETIVO ANGELA DAVIS: GRUPO \\
DE PESQUISA EM GÊNERO, RAÇA E \\
SUBALTERNIDADE \\
$\overline{\text { LíDERES }}$ \\
ANGELA LUCIA SILVA FIGUEIREDO; \\
ZELINDA DOS SANTOS BARROS \\
ÁREA \\
ANTROPOLOGIA \\
LINHAS DE PESQUISA \\
Gênero, cidadania e sexualidade; \\
Identidade, gênero e desigualdades \\
$\overline{\text { INSTITUIÇÃo }}$ \\
UFRB \\
Email: coletivoangeladavis@gmail.com; \\
Cobsite: https://www.facebook.com/ \\
coletivoangeladavis/
\end{tabular}

\begin{tabular}{|c|}
\hline GRUPO DE PESQUISA \\
FAGES - NÚCLEO DE FAMÍLIA, \\
GÊNERO E SEXUALIDADE \\
$\overline{\text { LÍDERES }}$ \\
RuSSELL PARRY SCOTT; JUDITH \\
CHAMBLISS HOFFNAGEL \\
$\overline{\text { ÁREA }}$ \\
CIÊNCIAS HUMANAS/ANTROPOLOGIA \\
LINHAS DE PESQUISA \\
Antropologia da educação, \\
interseccionalidades e desigualdades; \\
Estudos de família e parentesco; \\
Estudos de gênero; Estudos de \\
sexualidade \\
INSTITUIÇÃo \\
UFPE \\
Eomaite: https://www.ufpe.br/fages/ \\
\hline
\end{tabular}

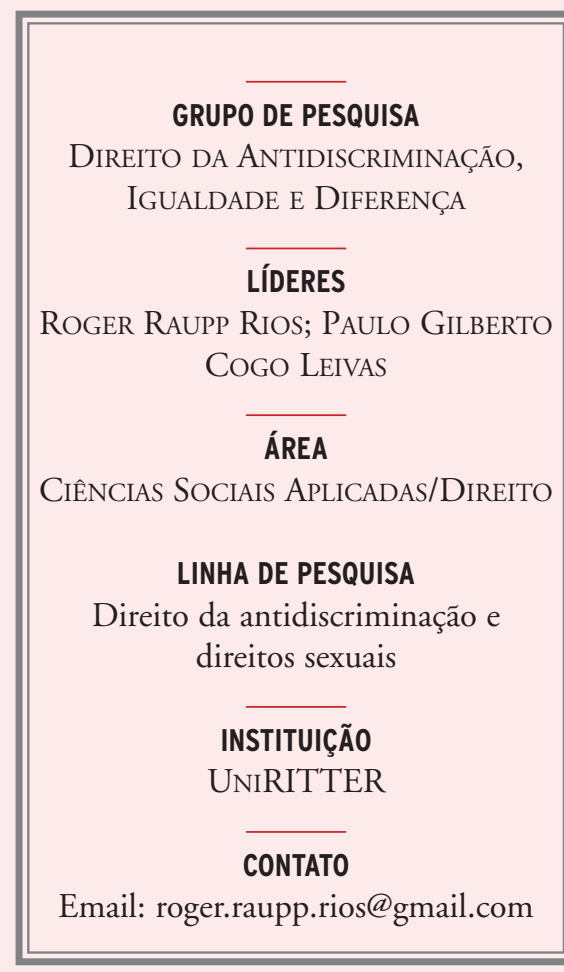

\section{GRUPO DE PESQUISA}

Grupo de Trabalho EM GÊNERO

\section{LÍDERES}

Benedito Medrado-Dantas; JORGE LUIZ CARDOSO

LYRA-DA-FONSECA

\section{ÁREA}

CiênCias Humanas/Psicologia

\section{LINHAS DE PESQUISA}

Estudos feministas; Homens, masculinidades e contextos sociais;

Processos psicossociais, poder e práticas coletivas; Produção de sentidos em saúde

\section{INSTITUIÇÃO \\ UFPE \\ CONTATOS \\ Email:}

masculinidades@gmail.com;

Website: www.genero.org.br e http:// gema-ufpe.blogspot.com.br/
GRUPO DE PESQUISA

ESCRITAS - FILOSOFIA,

GÊNERO E PSICANÁLISE

LÍDERES

Carla Rodrigues;

RAFAEL HADDOCK LOBO

ÁREA

CiênCias Humanas/Filosofia

\section{LINHAS DE PESQUISA}

As palavras como questão filosófica escrita e tradução; Epistemologia

feminista, desafios na filosofia

$$
\begin{gathered}
\text { INSTITUIÇÃO } \\
\text { UFRJ } \\
\overline{\text { CONTATOS }}
\end{gathered}
$$

Email: carla@ifcs.ufrj.br; Website: https://www.facebook.com/ escritas.filosofia/

\section{GRUPO DE PESQUISA}

GÊNero, Feminismo, Cultura

Política e Políticas Públicas

$$
\text { LÍDER }
$$

JUSSARA REIS PRÁ

\section{ÁREA}

CiênCIAS Humanas/CiênCIA POLÍTICA

\section{LINHAS DE PESQUISA}

Cultura política, gênero e opinião pública; Teoria política, democracia e participação

\section{INSTITUIÇÃO \\ UFRGS \\ CONTATOS}

Email: jussarapra@gmail.com;

Website: www6.ufrgs.br/ nucleomulher 

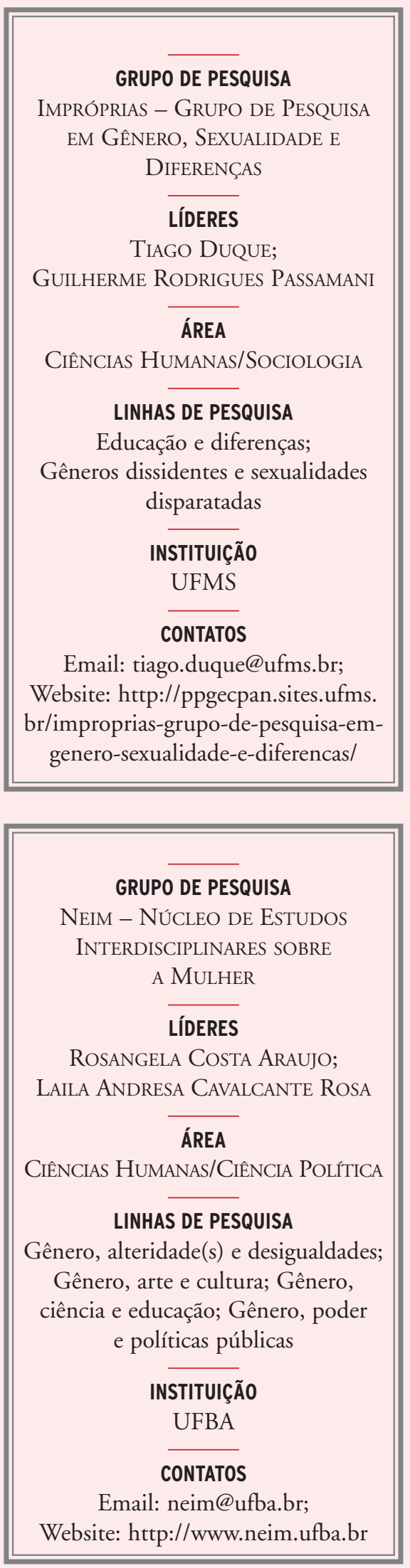

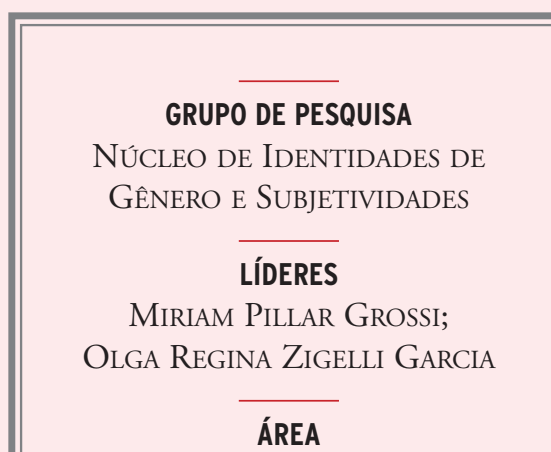

CiÊnCIAS Humanas/Antropologia

\section{LINHAS DE PESQUISA}

Educação e ensino de gênero; Famílias gays/lésbicas e outras formas alternativas de organização familiar;

Gênero e ciências; Movimentos feministas e GLBTT

\section{INSTITUIÇÃO \\ UFSC \\ CONTATOS}

Email: nigsnuc@cfh.ufsc.br; Website: http://nigs.paginas.ufsc.br

\begin{tabular}{|c|}
\hline GRUPO DE PESQUISA \\
PAGU - NÚCLEO DE ESTUDOS \\
DE GÊNERO \\
$\overline{\text { LídERES }}$ \\
ADRIANA GRACIA PISCITELLI; \\
GUITA GRIN DEBERT \\
$\overline{\text { ÁREA }}$
\end{tabular}

CiÊnCIAS Humanas/Antropologia

\section{LINHAS DE PESQUISA}

Sexualidades; Teorias feministas, de gênero e perspectivas disciplinares; Violência, tráfico de pessoas, prisōes, distribuição de justiça e práticas jurídicas
INSTITUIÇÃo
UNICAMP
CONTATOS

Email:pagu@unicamp.br; Website: http://www.pagu.unicamp.br
GRUPO DE PESQUISA

SEXgEN - SEXUALIDADES, CORPO E GÊNERO

LÍDERES

Fabiano de Souza Gontijo; Carla Ramos

ÁREA

CIÊNCIAS Humanas/ANTROPOlOGIA

\section{LINHAS DE PESQUISA}

Culturas identitárias homossexuais; Gênero, família e relações de poder;

Homoconjugalidades e homoparentalidades; Saúde, corpo e sexualidades

\section{INSTITUIÇÃO \\ UFPA \\ CONTATO}

Email: fgontijo2@hotmail.com

\section{GRUPO DE PESQUISA}

SER-TÃo - NúcleO de Estudos e Pesquisas em Gênero e SEXUALIDADE

\section{LÍDERES}

ELIANE GONÇALVES;

Camilo Albuquerque de Braz

\section{ÁREA}

CiÊnCIAS Humanas/SOCIOlOGIA

\section{LINHAS DE PESQUISA}

Gênero, teorias e metodologias feministas; Sexualidades, poder e subjetividades

\section{INSTITUIÇÃO UFG \\ CONTATOS}

Email: elianego@uol.com.br e brazcamilo@gmail.com; Website: www.sertao.ufg.br 